\title{
ABT-737, a Small Molecule Bcl-2/Bcl-xL Antagonist, Increases Antimitotic-Mediated Apoptosis in Human Prostate Cancer Cells
}

Castration-resistant prostate cancer (CRPC) expresses high levels of the anti-apoptotic proteins Bcl-2, Bcl-xL and Mcl-1, resulting in resistance to apoptosis and association with poor prognosis. Docetaxel, an antimitotic drug that is the first-line treatment strategy for CRPC, is known to provide a small survival benefit. However, docetaxel chemotherapy alone is not enough to counteract the high levels of Bcl-2/Bcl-xL/Mcl-1 present in CRPC. ABT-737 is a small molecule that binds to Bcl-2/Bcl-xL (but not Mcl-1) with high affinity and disrupts their interaction with pro-apoptotic Bax/Bak, thus enhancing apoptosis. Our results indicate that ABT-737 can sensitize androgen-dependent LNCaP and CRPC PC3 cells to docetaxel- and to the novel antimitotic ENMD-1198-mediated caspase-dependent apoptosis. CRPC DU145 cells, however, are more resistant to ABT-737 because they are Bax null and not because they express the highest levels of anti-apoptotic Mcl-1 (associated with ABT-737 resistance). Knockdown of Bax or Bak in LNCaP indicates that ABT-737-induced antimitotic enhancement of apoptosis is more dependent on the levels of Bax than Bak. Furthermore, we find that the ability of docetaxel to increase cyclin B1/Cdk1-mediated phosphorylation of Bcl-2/Bcl-xL and decrease Mcl-1 is required for ABT-737 to enhance apoptosis in PC3 cells, as determined by addition of Cdk1 inhibitor purvalanol A and expression of shRNA specific for cyclin B1. Overall, our data suggests that the high levels of anti-apoptotic proteins in Bax-expressing CRPC cells can be overcome by targeting Bcl-2/Bcl-xL with ABT-737 and Mcl-1 with antimitotics. 
1 Ricardo Parrondo ${ }^{1}$, Alicia de las Pozas ${ }^{1}$, Teresita Reiner ${ }^{1}$, and Carlos Perez-Stable ${ }^{1,2,3}$

$2 \quad{ }^{1}$ Geriatric Research, Education, and Clinical Center and Research Service, Bruce W. Carter

3 Veterans Affairs Medical Center, Miami, FL, USA 33125

$4 \quad{ }^{2}$ Division of Gerontology \& Geriatric Medicine, Department of Medicine, University of Miami

5 Miller School of Medicine, Miami FL, USA 33136

6 35ylvester Comprehensive Cancer Center, University of Miami Miller School of Medicine,

7 Miami FL, USA 33136

8 Corresponding author: Carlos Perez-Stable, Bruce W. Carter Veterans Affairs Medical Center,

9 GRECC (11-GRC), 1201 NW 16 Street, Miami, FL 33125 USA. Phone: (305) 575-7000,

10 extension 4391. E-mail: cperez@med.miami.edu

11 INTRODUCTION 
12 Prostate cancer (PCa) is a leading cause of cancer-related death in men and remains incurable in

13 the metastatic setting. Despite the initial response to androgen deprivation, PCa gradually

14 progresses to castration-resistant prostate cancer (CRPC) (Hadaschik \& Gleave, 2007;

15 Attar, Takimoto \& Gottardis, 2009). Docetaxel (Doc) is an FDA approved first-line treatment for

16 patients with CRPC but confers only a small survival benefit (Tannock et al., 2004). Once CRPC

17 patients fail Doc chemotherapy, only the Doc derivative cabazitaxel confers a slightly longer

18 overall survival (de Bone et al., 2010). To further improve overall survival of CRPC patients, a

19 better mechanistic understanding of Doc-induced CRPC cell death is required to develop more

20 effective combinatorial treatments.

21 The anti-proliferative activity of Doc results from its ability to bind microtubules and

22 disrupt mitosis (Jordan \& Wilson, 2004). Doc activates the mitotic checkpoint and blocks the

23 degradation of cyclin B1, leading to a prolonged activation of cyclin-dependant kinase 1 (Cdk1)

24 and increased mitotic arrest, followed by induction of mitotic catastrophe or apoptosis and also

25 lysosome-dependent cell death (Castedo et al., 2004; Mediavilla-Varela et al., 2009). We have

26 previously shown that small molecule inhibitors of Cdk1 can prevent Doc-mediated increase in

27 cyclin B1/Cdk1 activity and block induction of apoptosis in CRPC cells (Perez-Stable, 2006;

28 Gomez, de las Pozas \& Perez-Stable, 2006). This finding indicates that prolonged cyclin

29 B1/Cdk1 activity phosphorylates apoptotic signaling targets that can subsequently lead to

30 apoptosis, although the precise mechanisms have been difficult to determine. However, it is likely

31 that the mechanism involves substrates phosphorylated by cyclin B1/Cdk1.

32 The mitotic response to Doc shows little variation between cell types, whereas the ability to

33 subsequently undergo apoptosis shows large variations (hi , Orth \& Mitchison, 2008; Gascoigne

34 \& Taylor, 2008). This suggests that sensitivity to Doc depends to a greater extent on cell

35 type-specific apoptotic signaling mechanisms rather than on pathways that mediate mitotic arrest.

$36 \mathrm{Bcl}-2$, Bcl-xL, and Mcl-1 are anti-apoptotic proteins of the Bcl-2 family that are highly expressed 
in CRPC, resulting in resistance to apoptosis and association with poor prognosis (Karnak \& $X u$,

2011). Bcl-2, Bcl-xL, and Mcl-1 protect cells from apoptosis by binding to Bax and Bak, pro-apoptotic members of the Bcl-2 family, thereby preventing their homodimerization. Bax and Bak homodimers promote apoptosis by forming pores in the mitochondria, leading to mitochondrial outer membrane permeabilization (MOMP), cytochrome c release, and the activation of the caspase cascade (Chipuk et al., 2010).

Interestingly, microtubule inhibitors such as Doc induce Bcl-2 and Bcl-xL phosphorylation, thus antagonizing their anti-apoptotic function (Haldar, Jena \& Croce, 1995; Poruchynsky et al., 1998). Furthermore, phospho-defective Bcl-2 and Bcl-xL mutants block the pro-apoptotic effects of microtubule inhibitors, reinforcing the notion that mitotic phosphorylation of Bcl-2 and Bcl-xL inhibits their anti-apoptotic function (Haldar, Basu \& Croce, 1998; Basu \& Haldar,2003; Upreti, et al., 2008; Terrano, Upreti \& Chambers, 2010). Recent biochemical data now shows that cyclin B1/Cdk1 is the kinase that phosphorylates Bcl-2 and Bcl-xL during prolonged mitosis after treatment with the microtubule inhibitor vinblastine (Terrano, Upreti \& Chambers, 2010). In addition, cyclin B1/Cdk1 can also phosphorylate Mcl-1 to increase its degradation during prolonged mitotic arrest (Harley et al., 2010; Wertz et al., 2011). During a normal mitotic cell cycle phase, cyclin B1/Cdk1 only transiently phosphorylates Bcl-2, Bcl-xL, and Mcl-1, thus limiting the pro-cell death effect. Therefore, it is likely that during Doc-mediated mitotic arrest, prolonged cyclin B1/Cdk1 activity hyperphosphorylates Bcl-2, Bcl-xL, and Mcl-1to block their anti-apoptotic function, which is likely important for increasing cell death.

It is known that Doc chemotherapy alone is not enough to overcome the high levels of Bcl-2, Bcl-xL, and Mcl-1 present in patients with CRPC (Karnak \& Xu, 2011). A chemical library identified ABT-737 as a small molecule that binds Bcl-2/Bcl-xL (but not Mcl-1) with high affinity to disrupt their interaction with Bax/Bak and enhance the apoptotic signals, especially when combined with other chemotherapeutic drugs (Oltersdorf et al., 2005; Tagscherer et al., 
62 2008). The purpose of the present study is to determine whether ABT-737 combined with Doc or

63 a novel antimitotic ENMD-1198 (a more stable and potent derivative of 2-methoxyestradiol with

64 clinical promise [LaVallee et al., 2008; Zhou et al., 2011]) can overcome the high levels of

$65 \mathrm{Bcl}-2 / \mathrm{Bcl}-\mathrm{xL} / \mathrm{Mcl}-1$ in CRPC cells and enhance apoptotic cell death. Our results show that

66 ABT-737 enhances Doc and 1198-mediated caspase-dependent apoptosis in some PCa cells and

67 that this enhancement is dependent on expression of Bax and on cyclin B1/Cdk1-mediated

68 phosphorylation of Bcl-2/Bcl-xL and decrease in Mcl-1.

\section{MATERIALS AND METHODS}

\section{Reagents}

71 ABT-737 was obtained from Abbott Laboratories (Abbott Park, IL, USA), Doc from

72 Sanofi-Aventis (Bridgewater, NJ, USA), and ENMD-1198 from EntreMed, Inc (Rockville, MD,

73 USA). Q-VD pan-caspase inhibitor was purchased from R\&D Systems (Minneapolis, MN, USA);

74 purvalanol A from A.G. Scientific (San Diego, CA, USA); Trypan blue (0.4\%) from Invitrogen

75 (Grand Island, NY, USA); and Coomassie blue from EMD Chemicals (Billerica, MA, USA). All

76 other reagents were purchased from Sigma-Aldrich (St. Louis, MO, USA).

\section{Cell culture}

78 Human PCa cell lines LNCaP, DU145, and PC3 were obtained from the American Type Culture

79 Collection (Manassas, VA, USA) (van Bokhoven et al., 2003) and used within 6 months of

80 resuscitation of original cultures. All cells were maintained in RPMI 1640 medium (Invitrogen)

81 with 5\% fetal bovine serum (Hyclone, Waltham, MA), $100 \mathrm{U} / \mathrm{ml}$ penicillin, $100 \mu \mathrm{g} / \mathrm{ml}$

82 streptomycin, and $0.25 \mu \mathrm{g} / \mathrm{ml}$ amphotericin (Invitrogen). Unlike LNCaP, LN-AI cells are able to

83 grow for long-term in RPMI 1640 with 5\% charcoal-stripped fetal bovine serum (Hyclone) and

84 are referred to as LN-AI/CSS (Gomez, de las Pozas \& Perez-Stable, 2006). 


\section{Western blot analysis}

86 Preparation of total protein lysates and western blot analysis was done as previously described

87 (Gomez, de las Pozas \& Perez-Stable, 2006). The following antibodies were used: Bcl-2 (N-19),

88 Bax (N-20), Mcl-1 (S-19), cyclin B1 (GNS1), AIF (E-1), and horseradish peroxidase-conjugated

89 secondary antibody from Santa Cruz Biotechnology (Santa Cruz, CA, USA); Bak (NT) from

90 EMD Millipore (Billerica, MA, USA); Bcl-xL (\#610211), cytochrome c (7H8.2C12), Smac

91 (\#612245) from BD Biosciences (San Diego, CA, USA); cleaved PARP (9541), phospho-(Ser70)

92 Bcl-2 (2827), CoxIV (\#4844), Bid (\#2002) from Cell Signaling Technology (Danvers, MA,

93 USA); phospho-(Ser62) Bcl-xl (30655) from Abcam (Cambridge, MA, USA); and Noxa

94 (114C307.1) from Novus Biologicals (Littleton, CO, USA). After immunodetection, our

95 preference for loading controls was for staining of total proteins transferred to the membrane with

96 Coomassie blue because drug treatments often affect the levels of typical housekeeping proteins

97 such as actin or tubulin.

\section{$98 \quad$ ABT-737 cell viability assay}

99 LNCaP, DU145, and PC-3 cells were seeded in 96-well plates. The next day, fresh media

100 containing ABT-737 (1, 2.5, 5, $10 \mu \mathrm{M})$, or control (0.1\% DMSO) were added and cells incubated

101 for three days. The CellTiter Aqueous cell proliferation colorimetric method from Promega

102 (Madison, WI, USA) was used to determine cell viability, as per manufacturer's instructions.

103 Cell viability was normalized against the vehicle control and the data expressed as a percentage

104 of control from three independent experiments done in triplicate.

\section{Drug treatments}

106 PCa cells were cultured in media containing Doc (1nM), $1198(1 \mu \mathrm{M})$, ABT-737 (1 $\mu \mathrm{M})$, Doc or

1071198 + ABT-737, Q-VD $(10 \mu \mathrm{M})$, purvalanol A $(5 \mu \mathrm{M})$, Doc or 1198 + Q-VD or purvalanol A, or 
108 DMSO (0.1\%) control for varying times (24-72 h). In all the experiments, floating and

109 trypsinized attached cells were pooled for further analysis.

110 Trypan blue exclusion assay

111 Treated and control PCa cells were harvested, resuspended in PBS, diluted 1:1 in 0.4\% trypan

112 blue, dead blue and live non-blue cells immediately counted using a hemacytometer, and the \%

113 dead blue cells determined from at least three independent experiments done in duplicate.

\section{Annexin-FITC/propidium iodide (PI) flow cytometry}

115 Treated and control PCa cells were resuspended in binding buffer followed by the addition of 116 annexin V-FITC and PI (Annexin V Kit sc-4252 AK, Santa Cruz Biotechnology). After 20 min., cells

117 were analyzed by flow cytometry using a Coulter XL flow cytometer and the percentage of 118 annexin+ cells determined using WinMDI version 2.8 from two independent experiments done in 119 triplicate.

\section{Mitochondrial protein release assay}

121 Treated and control PCa cells were resuspended in a buffer containing 100-200 $\mu \mathrm{M}$ digitonin, 20

122 mM Hepes, pH 7.5, 10 mM KCl, 1.5 mM MgCl, 1 mM EGTA, 1 mM EDTA, 1 mM DTT, 250

$123 \mathrm{mM}$ sucrose, and protease inhibitors (Roche, Nutley, NJ) at $50 \mu \mathrm{l} / 1$ x10 cells. After 5 min on ice,

124 cells were centrifuged at 14k rpm 5 min and the supernatant used for western blot analysis.

125 Digitonin is a detergent that preferentially permeabilizes plasma membrane compared to

126 mitochondrial membrane (Gottlieb \& Granville, 2002).

\section{Retrovirus transduction of DU145 and LNCaP with Bax}

128 hBax C3-EGFP (Addgene, Cambridge, MA, USA; plasmid 19741) (Nechushtan et al., 1999) was

129 digested with HindIII, blunt-ended with Klenow DNA polymerase, digested with EcoRI, and the 
$130 \quad 0.6 \mathrm{~kb}$ Bax insert ligated into pBABE puro plasmid (BamH1-blunt/EcoRI) using

131 DNA ligase (New England Biolabs, Ipswich, MA, USA). Retrovirus

132 production and infection were done by transfecting HEK293T cells (American Type Culture

133 Collection) with $\mathrm{pBABE} / \mathrm{Bax}$ or $\mathrm{pBABE} / \mathrm{EV}$ (empty vector), pUMVC3, and

134 pCVM-VSV-G with FuGene HD (Roche), addition of filtered $(0.45 \mu \mathrm{M})$ media after $48 \mathrm{~h}$ to

135 DU145 and LNCaP cells, and selection with puromycin (Invitrogen; $2 \mu \mathrm{g} / \mathrm{ml}$ ) for 1 week. Cell

136 death in DU145/Bax, DU145/EV, LNCaP/Bax, and LNCaP/EV cells treated with DMSO control

137 were similar to parental cells (not shown).

\section{Lentiviral transduction of LNCaP, DU145, and PC3 with shRNA}

139 The shRNA design, lentivirus production, and infection were done as previously described (Stewart et 140 al, 2003). The following DNA oligonucleotides (Operon, Huntsville, AL, USA) targeting Mcl-1, Bax,

141 Bak, and cyclin B1 were cloned into pLKO.1 lentivirus vector: shMcl-1 (M2): cCGGGCTGGAGA

142 TTATCTCTCGGTACTCGAGTACCGAGAGATAATCTCCAGCTTTTTG; shMcl-1 (M3):

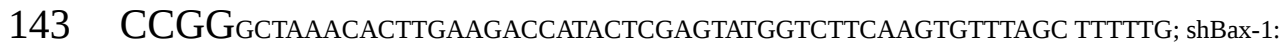

144 CCGGGCCGGAACTGATCAGAACCATCTCGAGATGGTTCTGATCAGTTCCGG CTTTTTG

145 (PC3); shBax-2: CCGGGCCTCAGGATGCGTCCACCAACTCGAGTTGGTGGACG

146 CATCCTGAGGCTTTTTG (LNCaP); shBak-1: CCGGTGGTACGAAGATTCTTCAAATCTC

147 GAGATTTGAAGAATCTTCGTACCATTTTTG (LNCaP); shBak-3: CCGGATGAGTACTTCA

148 CCAAGATTGCTCGAGCAATCTTGGTGAAGTACTCATTTTTTG (PC3); shCyclin B1-2: CCGG

149 GCCAAATACCTGATGGAACTACTCGAGTAGTTCCATCAGGTATTTGGCTTTTTG; and shCyclin

150 B1-3: CCGGGCCATCCTAATTGACTGGCTACTCGAGTAGCCAGTCAATTAGGATG GCTTTTTG.

151 The control shRNA was targeted against green fluorescent protein (GFP). For Mcl-1 knockdown in

152 DU145/Bax and PC3/shCyclin B1 cells (puromycin resistant), shMcl-1 and shGFP oligonucleotides 
153 were cloned into pLKO.1/hygromycin plasmid and transduced cells selected with $400 \mu \mathrm{g} / \mathrm{ml}$

154 hygromycin (Invitrogen) for two weeks. Cell death in DU145/shMcl-1, DU145/shGFP,

155 DU145/Bax/shMcl-1, DU145/Bax/shGFP, LNCaP/shBax, LNCaP/shBak, LNCaP/shGFP, PC3/shBax,

156 PC3/shBak, PC3/shCyclin B1, PC3/shGFP, PC3/shCyclin B1/shMcl-1, and PC3/shCyclin B1/shGFP

157 cells treated with DMSO control were similar to parental cells (not shown).

\section{Statistical analysis}

159 Statistical differences between drug-treated and control PCa cells were determined by two-tailed

160 Student's $t$-test (unequal variance) with $P<0.05$ considered significant.

\section{RESULTS}

CRPC cells express high anti-apoptotic Bcl-2/Bcl-xL/Mcl-1 and low or null pro-apoptotic Bax/Bak

Since ABT-737 is a Bcl-2/Bcl-xL antagonist that should promote the pro-apoptotic function of Bax/Bak, we compared the protein levels of Bcl-2,

Bcl-xL, Bax, and Bak in LNCaP, DU145, and PC3 cells. LNCaP cells are androgen-dependent, contain wild-type p53, and

exhibit higher sensitivity to antimitotic-mediated apoptosis relative to DU145 and PC3, which are 
178 the single agents in LNCaP and PC3 but not in DU145 cells (Fig. 2A, B; Supplemental Fig. S1A). Similar results were obtained in

179 LNCaP-AI/CSS, a CRPC variant of LNCaP that is more chemoresistant (Supplemental Fig. S1B). The pan-caspase inhibitor Q-VD (10 $\mu$ M)

180 blocked Doc + ABT-737-mediated cell death and cleaved-PARP, indicating that increased caspase activity was required (Fig. 2A, B).

181 ABT-737 targets the mitochondria to initiate the intrinsic pathway of apoptosis by

182 increasing the release of mitochondrial proteins such as cytochrome c, which in turn activates the caspase cascade (Chipuk et al., 2010). Our results indicated that ABT-737 enhanced

184 Doc-mediated release of cytochrome c, Smac (blocks inhibitor of apoptosis [IAP] family;

185 LaCasse et al., 2008), and apoptosis-inducing factor (AIF; translocates to nucleus to increase

186 DNA fragmentation; Susin et al., 1999) from the mitochondria in LNCaP and PC3 but not in

187 DU145 cells (Fig. 2C; supplemental Fig. S2). In addition, there was less cytoplasmic Bax protein in 188 Doc + ABT-737 treated LNCaP and PC3 cells, likely as a result of greater translocation of Bax to

189 the mitochondria. Thus, ABT-737 enhancement of Doc-mediated pro-apoptotic protein release

190 from the mitochondria correlates with increased apoptotic cell death in LNCaP and PC3 but not

191 in DU145.

Bax expression but not Mcl-1 suppression sensitizes DU145 to ABT-737 enhancement of Doc/1198-mediated apoptosis

We investigated the mechanisms why DU145 cells are more resistant to ABT-737. One possibility stems from the Bax null status of DU145 cells,

which would indicate that ABT-737 mediates its cytotoxicity via the Bax pathway. This is supported by a previous finding indicating that transient

transfection of Bax into DU145 cells increases sensitivity to ABT-737 + TRAIL (Song, Kandasamy \& Kraft, 2008). Another possibility

is that ABT-737 resistance of DU145 cells arises from elevated Mcl-1, which unlike Bcl-2/Bcl-xL does not interact with ABT-737 and may

therefore block the ability of ABT-737 to increase apoptosis (van Delft et al., 2006; Chen et al, 2007; Lestini et al., 2009; Hauck et

al., 2009; Yecies et al., 2010). To address these possibilities, we isolated DU145 cells stably expressing Bax and DU145 cells with stable 
206 ABT-737 inhibits the interactions of Bcl-2/Bax and Bcl-xL/Bak, thus allowing Bax and Bak to

207 induce MOMP and apoptosis (Oltersdorf et al., 2005; Tagscherer et al., 2008). To further

208 investigate the relative importance of Bax versus Bak in mediating ABT-737 enhancement of

209 Doc/1198-mediated cell death in PCa cells, we isolated LNCaP and PC3 cells stably expressing either

210 shBax or shBak. Results showed that knockdown of Bax lowered Doc/1198 + ABT-737-mediated cell death and cleaved-PARP in both LNCaP

211 and PC3 cells compared to the negative control shGFP cells (Fig. 4A). Knockdown of Bak also lowered Doc/1198 + ABT-737-induced cell death

212 and cleaved-PARP in PC3 cells but had no significant effects in LNCaP cells (Fig. 4B). These results suggest that ABT-737 enhancement of

213 Doc/1198-mediated apoptosis in LNCaP cells is more dependent on Bax than to Bak but PC3 cells are dependent on both Bax and Bak.

\section{Doc counteracts the ABT-737-mediated increase in Mcl-1}

215 We determined if Doc and Doc + ABT-737 had any effects on the protein levels of Bcl-2 family

216 members in LNCaP and PC3 cells. Interestingly, Doc decreased and ABT-737 increased Mcl-1

217 but the combination of Doc + ABT-737 lowered Mcl-1 (Fig. 5). The mechanism why ABT-737

218 alone increases Mcl-1 protein is not known but may reflect the observation that acquired

219 resistance to ABT-737 involves increased Mcl-1 (Yecies et al., 2010). There were no clear differences

220 in the protein levels of Bcl-2, Bcl-xL, Bax, Bak, Bid, and Noxa with the exception in LNCaP

221 where there was less Bcl-2 (Doc, $24 \mathrm{~h}$ ) and Bak (Doc+ ABT-737, $48 \mathrm{~h}$ ). These results suggest that

222 the Doc + ABT-737 enhancement of apoptosis may depend upon the ability of Doc to counteract

223 the ABT-737-mediated increase in Mcl-1.

224

225

226

227

228

229

230

231

ABT-737-mediated enhancement of Doc-induced apoptosis is dependent on cyclinB1/Cdk1-mediated phosphorylation of Bcl-2/Bcl-xL and decrease of Mcl-1

Small molecule inhibitors of Cdk1 prevent Doc-mediated increase in cyclin B1/Cdk1 activity and blocks induction of apoptosis in CRPC cells (Perez-Stable, 2006; Gomez, de las Pozas \&

Perez-Stable, 2006). We investigated whether cyclin B1/Cdk1-mediated increase in Bcl-2/Bcl-xL phosphorylation and decrease in Mcl-1 is important for the ABT-737 enhancement of

Doc-induced apoptosis. Treatment (Doc alone and Doc + ABT-737) of LNCaP and PC3 but not DU145 cells increased phospho (P)-Bcl-2, whereas the levels of P-Bcl-xL was similar in all three 
232 cell lines (Supplemental Fig. S6). Addition of $5 \mu \mathrm{M}$ purvalanol A, a specific inhibitor of cyclin

233 B1/Cdk1 activity (Gray et al., 1998) blocked Doc + ABT-737 cell death and the increase in

234 P-Bcl-2/P-Bcl-xL in PC3 cells (Fig. 6A). However, purvalanol A increased Mcl-1 protein in Doc

235 + ABT-737 treated PC3 cells, suggesting that this may also play an important role in blocking 236 apoptotic cell death (Fig. 6A).

237 To further determine whether the Doc-mediated increase in cyclin B1/Cdk1 activity,

238 P-Bcl-2/P-Bcl-xL, and decrease in Mcl-1 is important for ABT-737 + Doc cell death, we isolated

239 PC3 cells stably expressing shCyclin B1. Results showed that knockdown of cyclin B1 lowered Doc + ABT-737 cell death, cleaved-PARP,

240 and P-Bcl-2/P-Bcl-xL in PC3/shCyclin B1 cells compared to shGFP control cells (Fig. 6B). However, given that there is less

241 cyclin B1 to mediate Cdk1 degradation of Mcl-1 by Doc, it is not surprising that Mcl-1 levels are

242 slightly higher in Doc + ABT-737 treated PC3/shCyclin B1 compared to shGFP cells (Fig. 6B). We then

243 isolated PC3/shCyclin B1 cells stably expressing shMcl-1 and the results showed that Doc + ABT-737 increased cell death (67\%) nearly to the

244 levels of PC3/shMcl-1 cells (83\%) (Fig. 7; Supplemental Fig. S5B). Overall, these results suggest that the ABT-737 enhancement of

245 Doc-mediated apoptosis is more dependent on the ability of cyclin B1/Cdk1 to increase the degradation of Mcl-1 than to phosphorylate

246 Bcl-2/Bcl-xL.

DISCUSSION

Progression of PCa to CRPC is often associated with overexpression of the anti-apoptotic proteins Bcl-2, Bcl-xL, and Mcl-1, resulting in resistance to apoptosis and poor prognosis

251 (Karnak \& Xu, 2011). Doc is an antimitotic drug approved for the treatment of CRPC but the

252 high levels of Bcl-2/Bcl-xL/Mcl-1 confers a block, resulting in less apoptosis and reduced

253 efficacy. Here we report that the Bcl-2/Bcl-xL small molecule antagonist ABT-737 can overcome

254 this block and increase Doc and 1198 (new antimitotic)-induced apoptosis in CRPC PC3 and

255 LN-AI/CSS cells. However, another CRPC cell line, DU145, is more resistant to ABT-737 due to

256 the lack of the pro-apoptotic Bax protein and the combination with Doc or 1198 did not further

257 increase apoptosis. Our results also indicate that the ABT-737 enhancement of Doc-mediated 
258 apoptosis in LNCaP and PC3 cells is dependent upon the ability of Doc to constitutively activate

259 cyclin B1/Cdk1 activity and hyperphosphorylate Bcl-2/Bcl-xL and decrease Mcl-1. Overall, these

260 results provide mechanistic insight into how ABT-737 can sensitize Bax expressing CRPC cells

261 to Doc/1198 treatment by overcoming the block in apoptosis due to the high levels of

262 Bcl-2/Bcl-xL/Mcl-1 (Fig. 8).

263 There is strong evidence that Bcl-2/Bcl-xL overexpression is important for CRPC

264 progression (Miyake, Monia \& Gleave, 2000). Our results indicate that the commonly utilized

265 CRPC cell lines DU145 and PC3 express higher levels of Bcl2/Bcl-xL and lower levels of

266 Bax/Bak when compared to androgen-dependent LNCaP cells (Fig. 1A). Several reports indicate

267 that the efficacy of ABT-737 positively correlates with Bcl-2 levels, i.e., the higher the Bcl-2 the

268 better the response to ABT-737 alone or in combination with other chemotherapeutic agents (Del

269 Gaizo Moore et al., 2008; Hann et al., 2008; Mason et al., 2009; Oakes et al., 2012). This

270 correlation does not appear to apply to PCa cell lines as LNCaP has the lowest levels of Bcl-2 yet

271 are as sensitive to ABT-737 as PC3 cells with the highest level of Bcl-2 (Fig. 1).

272 Numerous reports indicate that Mcl-1 overexpression in a variety of cancers can mediate

273 resistance to ABT-737 (van Delft et al., 2006; Chen et al, 2007; Lestini et al, 2009; Hauck et al., 2009; Yecies et al.,

274 2010). However, our results indicate that DU145 cells are more resistant to ABT-737 as a single

275 agent and in combination with Doc/1198 due to the lack of Bax expression and not because they

276 express the highest levels of Mcl-1. In contrast, knockdown of Mcl-1 in Bax expressing LNCaP

277 and PC3 cells enhances sensitivity to Doc/1198 + ABT-737. It is possible that in PCa cells, the

278 complete loss of Bax (as in DU145) is a more dominant mechanism for ABT-737 resistance

279 compared to overexpression of Mcl-1. In PC3, however, the Bax levels are much lower than in

280 LNCaP, yet both cells respond similarly to ABT-737, suggesting that only a low amount of Bax

281 protein is required. In PCa clinical biopsies, loss of Bax immunostaining relative to normal

282 non-cancer prostate epithelium is a useful biomarker for categorizing patient risk and response to 
283 radiation therapy (Pollack et al., 2003; Khor et al., 2007). Therefore, determining the percentage

284 of Bax negative cells in human PCa specimens may provide a useful biomarker for identifying

285 patients that should respond to ABT-737 treatment.

286 During a normal mitotic cell cycle phase, cyclin B1/Cdk1 transiently phosphorylates

287 numerous substrates, including the anti-apoptotic proteins Bcl-2, Bcl-xL, and Mcl-1. Antimitotic

288 drugs such as Doc or 1198 can prevent the degradation of cyclin B1, resulting in constitutively

289 active Cdk1 activity and hyperphosphorylation of $\mathrm{Bcl}-2 / \mathrm{Bcl}-\mathrm{xL} / \mathrm{Mcl}-1$. Our results suggest that

290 cyclinB1/Cdk1-mediated phosphorylation of Bcl-2/Bcl-xL is important for the enhancement of

291 apoptosis by the Doc + ABT-737 combination in LNCaP and PC3 cells. This supports previous

292 results that the antimitotic drug vinblastine promotes apoptosis in HeLa cervical carcinoma cells

293 by a similar mechanism (Terrano, Upreti \& Chambers, 2010). More recently, the sensitivity of

294 cancer cells to antimitotic drugs has been shown to have a dependence on the ability of cyclin

295 B1/Cdk1 to phosphorylate and increase the degradation of Mcl-1 in order to enhance apoptosis

296 (Harley et al., 2010; Wertz et al., 2011). Our results suggest that the antimitotic-mediated increase

297 in cyclin B1/Cdk1 activity and reduction of Mcl-1 protein counteracts the increase of Mcl-1 by

298 ABT-737, resulting in enhanced apoptosis. Antimitotic drugs or radiation treatment also enhance

299 cyclin B1/Cdk1 phosphorylation of numerous other substrates that are implicated in either

300 increasing or decreasing apoptosis (O'Connor et al., 2000; Konishi et al., 2002; Berndtsson et al.,

301 2005; Allan \& Clarke, 2009; Andersen et al., 2009; Nantajit et al., 2010). Overall, our results suggest that

302 the cyclin B1/Cdk1-mediated hyperphosphorylation of Bcl-2, Bcl-xL, and Mcl-1 is a major

303 mechanism linking mitotic arrest to the induction of apoptosis in PCa cells.

304 Although our results do not address whether the Doc/1198 + ABT-737 combination will be

305 effective in vivo, there is evidence in lung, leukemia, prostate, and breast cancer to indicate that

306 the antimitotic + ABT-737 combination should prove to be effective in animal models of PCa

307 (Oakes et al., 2012; Shoemaker et al., 2006; Kang et al., 2007; Bray et al., 2009). Navitoclax, 
previously known as ABT-263, is an orally bioavailable analog of ABT-737 with identical

309 function that is currently in Phase II trials for refractory lymphoid malignancies and solid tumors

310 and appears to be a promising agent for use in combination with Doc (Tse et al., 2008; Shi et al.,

311 2011). Our results provide a strong mechanistic rationale for combining targeted chemotherapy

312 against Bcl2/Bcl-xL, as with navitoclax, with the currently approved drug for CRPC Doc, which

313 targets the destruction of Mcl-1, a navitoclax resistance factor. With the addition of cabazitaxel to

314 help in the treatment of patients that develop Doc-resistance, it is also likely that the combination

315 of cabazitaxel and navitoclax will further improve overall survival (de Bono et al., 2010).

316 ACKNOWLEDGEMENTS

317 We thank Dr. Pryamvada Rai for critical reading of the manuscript and helpful suggestions;

318 Deanna Palenzuela for technical assistance; Ron Hamelik for assistance with flow cytometry; and

319 Drs. Bernard Roos and Guy Howard for support.

\section{REFERENCES}

Allan LA, Clarke PR. 2007. Phosphorylation of caspase-9 by CDK1/cyclin B1 protects mitotic cells against apoptosis. Molecular Cell

Andersen JL, Johnson CE, Freel CD, Parrish AB, Day JL, Buchakjian MR, Nutt LK, Thompson JW, Moseley MA,

324 Kornbluth S. 2009. Restraint of apoptosis during mitosis through interdomain phosphorylation of caspase-2. EMBO Journal

325 28:3216-3227.

326 Attar RM, Takimoto CH, Gottardis MM. 2009. Castration-resistant prostate cancer: locking up

327 the molecular escape routes. Clinical Cancer Research 15:3251-3255.

328 Basu A, Haldar S. 2003. Identification of a novel Bcl-xL phosphorylation site regulating the

329 sensitivity of taxol- or 2-methoxyestradiol-induced apoptosis. FEBS Letters 538:41-47. 
Berndtsson M, Konishi Y, Bonni A, Hagg M, Shoshan M, Linder S, Havelka AM. 2005.

331 Phosphorylation of BAD at Ser-128 during mitosis and paclitaxel-induced apoptosis. FEBS

332 Letters 579:3090-3094.

333 Bray K, Chen HY, Karp CM, May M, Ganesan S, Karantza-Wadsworth V, DiPaola RS,

334 White E. 2009. Bcl-2 modulation to activate apoptosis in prostate cancer. Molecular Cancer

335 Research 7:1487-1496.

336 Castedo M, Perfettini JL, Roumier T, Andreau K, Medema R, Kroemer G. 2004. Cell death

337 by mitotic catastrophe: a molecular definition. Oncogene 23:2825-2837.

338 Chen S, Dai Y, Harada H, Dent P, Grant S. 2007. Mcl-1 down-regulation potentiates ABT-737

339 lethality by cooperatively inducing Bak activation and Bax translocation. Cancer Research

$340 \quad 67: 782-791$.

341 Chipuk JE, Moldoveanu T, Llambi F, Parsons MJ, Green DR. 2010. The BCL-2 family

342 reunion. Molecular Cell 37:299-310.

343 de Bono JS, Oudard S, Ozguroglu M, Hansen S, Machiels JP, Kocak I, Gravis G, Bodrogi I,

344 Mackenzie MJ, Shen L, Roessner M, Gupta S, Sartor AO; TROPIC Investigators. 2010.

345 Prednisone plus cabazitaxel or mitoxantrone for metastatic castration-resistant prostate cancer

346 progressing after docetaxel treatment: a randomised open-label trial. Lancet 376:1147-1154.

347 Del Gaizo Moore V, Schlis KD, Sallan SE, Armstrong SA, Letai A. 2008. BCL-2 dependence

348 and ABT-737 sensitivity in acute lymphoblastic leukemia. Blood 111:2300-2309.

349 Gascoigne KE, Taylor SS. 2008. Cancer cells display profound intra- and interline variation

350 following prolonged exposure to antimitotic drugs. Cancer Cell 14:111-122. 
351 Gomez LA, de las Pozas A, Perez-Stable C. 2006. Sequential combination of flavopiridol and

352 docetaxel reduces the levels of XIAP and AKT proteins and stimulates apoptosis in human

353 LNCaP prostate cancer cells. Molecular Cancer Therapeutics 5:1216-1226.

354 Gottlieb RA, Granville DJ. 2002. Analyzing mitochondrial changes during apoptosis. Methods 355 26:341-347.

356 Gray NS, Wodicka L, Thunnissen AM, Norman TC, Kwon S, Espinoza FH, Morgan DO,

357 Barnes G, LeClerc S, Meijer L, Kim SH, Lockhart DJ, Schultz PG. 1998. Exploiting

358 chemical libraries, structure, and genomics in the search for kinase inhibitors. Science 281:

$359533-538$.

360 Hadaschik BA, Gleave ME. 2007. Therapeutic options for hormone-refractory prostate cancer 361 in 2007. Urologic Oncology 25:413-419.

362 Haldar S, Basu A, Croce CM. 1998. Serine-70 is one of the critical sites for drug-induced Bcl2 363 phosphorylation in cancer cells. Cancer Research 58:1609-1615.

364 Haldar S, Jena N, Croce CM. 1995. Inactivation of Bcl-2 by phosphorylation. Proceedings of 365 the National Academy of Sciences, USA 92: 4507-4511.

366 Hann CL, Daniel VC, Sugar EA, Dobromilskaya I, Murphy SC, Cope L, Lin X, Hierman 367 JS, Wilburn DL, Watkins DN, Rudin CM. 2008. Therapeutic efficacy of ABT-737, a selective 368 inhibitor of BCL-2, in small cell lung cancer. Cancer Research 68:2321-2328.

369 Harley ME, Allan LA, Sanderson HS, Clarke PR. 2010. Phosphorylation of Mcl-1 by

370 CDK1-cyclin B1 initiates its Cdc20-dependent destruction during mitotic arrest. EMBO Journal 371 29: 2407-2420. 
372 Hauck P, Chao BH, Litz J, Krystal GW. 2009. Alterations in the Noxa/Mcl-1 axis determine

373 sensitivity of small cell lung cancer to the BH3 mimetic ABT-737. Molecular Cancer

374 Therapeutics 8:883-892.

375 Jordan MA, Wilson L. 2004. Microtubules as a target for anticancer drugs. Nature Reviews

376 Cancer 4:253-265.

377 Kang MH, Kang YH, Szymanska B, Wilczynska-Kalak U, Sheard MA, Harned TM, Lock

378 RB, Reynolds CP. 2007. Activity of vincristine, L-ASP, and dexamethasone against acute

379 lymphoblastic leukemia is enhanced by the BH3-mimetic ABT-737 in vitro and in vivo. Blood 380 110:2057-2066.

381 Karnak D, Xu L. 2010. Chemosensitization of prostate cancer by modulating Bcl-2 family

382 proteins. Current Drug Targets 11:699-707.

\section{Khor LY, Moughan J, Al-Saleem T, Hammond EH, Venkatesan V, Rosenthal SA, Ritter}

384 MA, Sandler HM, Hanks GE, Shipley WU, Pollack A. 2007. Bcl-2 and Bax expression predict

385 prostate cancer outcome in men treated with androgen deprivation and radiotherapy on radiation

386 therapy oncology group protocol 92-02. Clinical Cancer Research 13:3585-3590.

387 Konishi Y, Lehtinen M, Donovan N, Bonni A. 2002. Cdc2 phosphorylation of BAD links the

388 cell cycle to the cell death machinery. Molecular Cell 9:1005-1016.

389 LaCasse EC, Mahoney DJ, Cheung HH, Plenchette S, Baird S, Korneluk RG. 2008.

390 IAP-targeted therapies for cancer. Oncogene 27:6252-6275.

391 LaVallee TM, Burke PA, Swartz GM, Hamel E, Agoston GE, Shah J, Suwandi L, Hanson

392 AD, Fogler WE, Sidor CF, Treston AM. 2008. Significant antitumor activity in vivo following

393 treatment with the microtubule agent ENMD-1198. Molecular Cancer Therapeutics

$394 \quad 7: 1472-1482$. 
Lestini BJ, Goldsmith KC, Fluchel MN, Liu X, Chen NL, Goyal B, Pawel BR, Hogarty MD.

396

397

398

399

400

401

402

403

404

405

406

407

408

409

410

411

412

413

414

415

416

417

2009. Mcl1 downregulation sensitizes neuroblastoma to cytotoxic chemotherapy and small molecule Bcl2-family antagonists. Cancer Biology \& Therapy 8:1587-1595.

Mason KD, Khaw SL, Rayeroux KC, Chew E, Lee EF, Fairlie WD, Grigg AP, Seymour JF,

Szer J, Huang DC, Roberts AW. 2009. The BH3 mimetic compound, ABT-737, synergizes with a range of cytotoxic chemotherapy agents in chronic lymphocytic leukemia. Leukemia 23:2034-2041.

Mediavilla-Varela M, Pacheco FJ, Almaguel F, Perez J, Sahakian E, Daniels TR, Leoh LS, Padilla A, Wall NR, Lilly MB, De Leon M, Casiano CA. 2009. Docetaxel-induced prostate cancer cell death involves concomitant activation of caspase and lysosomal pathways and is attenuated by LEDGF/p75. Mol Cancer 8:68.

Miyake H, Monia BP, Gleave ME. 2000. Inhibition of progression to androgen-independence by combined adjuvant treatment with antisense BCL-XL and antisense Bcl-2 oligonucleotides plus taxol after castration in the Shionogi tumor model. International Journal of Cancer 86:855-862.

Nantajit D, Fan M, Duru N, Wen Y, Reed JC, Li JJ. 2010. Cyclin B1/Cdk1 phosphorylation of mitochondrial p53 induces anti-apoptotic response. PLoS One 5:e12341.

Nechushtan A, Smith CL, Hsu YT, Youle RJ. 1999. Conformation of the Bax C-terminus regulates subcellular location and cell death. EMBO Journal 18:2330-2341.

Oakes SR, Vaillant F, Lim E, Lee L, Breslin K, Feleppa F, Deb S, Ritchie ME, Takano E, Ward T, Fox SB, Generali D, Smyth GK, Strasser A, Huang DC, Visvader JE, Lindeman GJ. 2012. Sensitization of BCL-2-expressing breast tumors to chemotherapy by the BH3 mimetic ABT-737. Proceedings of the National Academy of Sciences USA 109:2766-2771. 
419 DC. 2000. Regulation of apoptosis at cell division by p34cdc2 phosphorylation of survivin.

420 Proceedings of the National Academy of Sciences USA 97:13103-13107.

421 Oltersdorf T, Elmore SW, Shoemaker AR, Armstrong RC, Augeri DJ, Belli BA, Bruncko M, 422 Deckwerth TL, Dinges J, Hajduk PJ, Joseph MK, Kitada S, Korsmeyer SJ, Kunzer AR, 423 Letai A, Li C, Mitten MJ, Nettesheim DG, Ng S, Nimmer PM, O'Connor JM, Oleksijew A, 424 Petros AM, Reed JC, Shen W, Tahir SK, Thompson CB, Tomaselli KJ, Wang B, Wendt MD, 425 Zhang H, Fesik SW, Rosenberg SH. 2005. An inhibitor of Bcl-2 family proteins induces 426 regression of solid tumours. Nature 435:677-681.

Perez-Stable C. 2006. 2-Methoxyestradiol and paclitaxel have similar effects on the cell cycle 428 and induction of apoptosis in prostate cancer cells. Cancer Letters 231:49-64.

Pollack A, Cowen D, Troncoso P, Zagars GK, von Eschenbach AC, Meistrich ML, McDonnell T. 2003. Molecular markers of outcome after radiotherapy in patients with prostate 431 carcinoma: Ki-67, bcl-2, bax, and bcl-x. Cancer 97:1630-1638.

432 Poruchynsky MS, Wang EE, Rudin CM, Blagosklonny MV, Fojo T. 1998. Bcl-xL is 433 phosphorylated in malignant cells following microtubule disruption. Cancer Research 434 58:3331-3338.

435 Reiner T, de las Pozas A, Gomez LA, Perez-Stable C. 2009. Low dose combination of 436 2-methoxyestradiol and docetaxel can block prostate cancer cells in mitosis and induce apoptosis.

437 Cancer Letters 276:21-31.

438 Shi J, Orth JD, Mitchison T. 2008. Cell type variation in responses to antimitotic drugs that 439 target microtubules and kinesin-5. Cancer Research 68:3269-3276. 
440 Shi J, Zhou Y, Huang HC, Mitchison TJ. 2011. Navitoclax (ABT-263) accelerates apoptosis

441 during drug-induced mitotic arrest by antagonizing Bcl-xL. Cancer Research 71:4518-4526.

442 Shoemaker AR, Oleksijew A, Bauch J, Belli BA, Borre T, Bruncko M, Deckwirth T, Frost

443 DJ, Jarvis K, Joseph MK, Marsh K, McClellan W, Nellans H, Ng S, Nimmer P, O'Connor

444 JM, Oltersdorf T, Qing W, Shen W, Stavropoulos J, Tahir SK, Wang B, Warner R, Zhang

445 H, Fesik SW, Rosenberg SH, Elmore SW. 2006. A small-molecule inhibitor of Bcl-XL

446 potentiates the activity of cytotoxic drugs in vitro and in vivo. Cancer Research 66:8731-8739.

447 Song JH, Kandasamy K, Kraft AS. 2008. ABT-737 induces expression of the death receptor 5 448 and sensitizes human cancer cells to TRAIL-induced apoptosis. Journal of Biological Chemistry 449 283:25003-25013.

450 Stewart SA, Dykxhoorn DM, Palliser D, Mizuno H, Yu EY, An DS, Sabatini DM, Chen IS, 451 Hahn WC, Sharp PA, Weinberg RA, Novina CD. 2003. Lentivirus-delivered stable gene 452 silencing by RNAi in primary cells. RNA 9:493-501.

453 Susin SA, Lorenzo HK, Zamzami N, Marzo I, Snow BE, Brothers GM, Mangion J, Jacotot 454 E, Costantini P, Loeffler M, Larochette N, Goodlett DR, Aebersold R, Siderovski DP, 455 Penninger JM, Kroemer G. 1999. Molecular characterization of mitochondrial 456 apoptosis-inducing factor. Nature 397:441-446.

457 Tagscherer KE, Fassl A, Campos B, Farhadi M, Kraemer A, Böck BC, Macher-Goeppinger

458 S, Radlwimmer B, Wiestler OD, Herold-Mende C, Roth W. 2008. Apoptosis-based treatment 459 of glioblastomas with ABT-737, a novel small molecule inhibitor of Bcl-2 family proteins.

460 Oncogene 27:6646-6656. 
461 Tang DG, Li L, Chopra DP, Porter AT. 1998. Extended survivability of prostate cancer cells in

462 the absence of trophic factors: increased proliferation, evasion of apoptosis, and the role of

463 apoptosis proteins. Cancer Research 58:3466-3479.

464 Tannock IF, de Wit R, Berry WR, Horti J, Pluzanska A, Chi KN, Oudard S, Théodore C,

465 James ND, Turesson I, Rosenthal MA, Eisenberger MA; TAX 327 Investigators. 2004.

466 Docetaxel plus prednisone or mitoxantrone plus prednisone for advanced prostate cancer. New

467 England Journal of Medicine 351:1502-1512.

468 Terrano DT, Upreti M, Chambers TC. 2010. Cyclin-dependent kinase 1-mediated

469 Bcl-xL/Bcl-2 phosphorylation acts as a functional link coupling mitotic arrest and apoptosis.

470 Molecular and Cellular Biology 30:640-656.

471 Tse C, Shoemaker AR, Adickes J, Anderson MG, Chen J, Jin S, Johnson EF, Marsh KC,

472 Mitten MJ, Nimmer P, Roberts L, Tahir SK, Xiao Y, Yang X, Zhang H, Fesik S, Rosenberg

473 SH, Elmore SW. 2008. ABT-263: a potent and orally bioavailable Bcl-2 family inhibitor. Cancer

474 Research 68:3421-3428.

475 Upreti M, Galitovskaya EN, Chu R, Tackett AJ, Terrano DT, Granell S, Chambers TC.

476 2008. Identification of the major phosphorylation site in Bcl-xL induced by microtubule

477 inhibitors and analysis of its functional significance. Journal of Biological Chemistry

$478 \quad$ 283:35517-35525.

479 van Bokhoven A, Varella-Garcia M, Korch C, Johannes WU, Smith EE, Miller HL,

480 Nordeen SK, Miller GJ, Lucia MS. 2003. Molecular characterization of human prostate

481 carcinoma cell lines. Prostate 57:205-225.

482 van Delft MF, Wei AH, Mason KD, Vandenberg CJ, Chen L, Czabotar PE, Willis SN, Scott

483 CL, Day CL, Cory S, Adams JM, Roberts AW, Huang DC. 2006. The BH3 mimetic ABT-737 
484 targets selective Bcl-2 proteins and efficiently induces apoptosis via Bak/Bax if Mcl-1 is

485 neutralized. Cancer Cell 10:389-399.

486 Wertz IE, Kusam S, Lam C, Okamoto T, Sandoval W, Anderson DJ, Helgason E, Ernst JA,

487 Eby M, Liu J, Belmont LD, Kaminker JS, O'Rourke KM, Pujara K, Kohli PB, Johnson AR,

488 Chiu ML, Lill JR, Jackson PK, Fairbrother WJ, Seshagiri S, Ludlam MJ, Leong KG,

489 Dueber EC, Maecker H, Huang DC, Dixit VM. 2011. Sensitivity to antitubulin

490 chemotherapeutics is regulated by MCL1 and FBW7. Nature 471:110-114.

491 Yecies D, Carlson NE, Deng J, Letai A. 2010. Acquired resistance to ABT-737 in lymphoma

492 cells that up-regulate MCL-1 and BFL-1. Blood 115:3304-3313.

493 Zhou Q, Gustafson D, Nallapareddy S, Diab S, Leong S, Lewis K, Gore L, Messersmith

494 WA, Treston AM, Eckhardt SG, Sidor C, Camidge DR. 2011. A phase I dose-escalation, safety

495 and pharmacokinetic study of the 2-methoxyestradiol analog ENMD-1198 administered orally to

496 patients with advanced cancer. Investigational New Drugs 29:340-346.

\section{FIGURE LEGENDS}

498 Figure 1 Bcl-2 family protein levels and sensitivity to ABT-737 in PCa cells. (A) Western blot analysis showing that the levels of anti-apoptotic Bcl-2 and Bcl-xL proteins are higher in DU145 (D) and PC3 (P) CRPC cells compared to androgen-dependent LNCaP (L) cells, whereas anti-apoptotic Mcl-1 is highest in DU145. The levels of pro-apoptotic Bax and Bak are higher in

502 LNCaP compared to DU145 (Bax null) and PC3. After detection, Coomassie blue stain of total

503 protein transferred to the membrane is the loading control. (B) Cell viability assay showing that

504 LNCaP and PC3 are similarly sensitive to various concentrations of ABT-737 (1-5 $\mu \mathrm{M}$; three 505 days), whereas DU145 is more resistant. 
507 in DU145 PCa cells. (A) Trypan blue exclusion assay showing that the combination of $1 \mathrm{nM}$ Doc

$508+1 \mu \mathrm{M}$ ABT-737 increases total cell death in LNCaP and PC3 but not in DU145 compared to

509 Doc or ABT-737 alone $\left(*, P<2 \times 10^{-4}\right)$. LNCaP were treated for 48 h and DU145 and PC3 for 72

510 h. Pan-caspase inhibitor Q-VD $(10 \mu \mathrm{M})$ blocks the Doc + ABT-737 increase in cell death.

511 Western blot analysis showing that Doc + ABT-737 increases cleaved-PARP (cP) levels in

512 LNCaP and PC3 but not in DU145 compared to Doc or ABT-737 alone. Q-VD blocks the Doc +

513 ABT-737 increase in cP in all cells. (B) Flow cytometric analysis showing higher annexin-FITC

514 stained LNCaP and PC3 but not DU145 cells treated with Doc + ABT-737 compared to Doc or

515 ABT-737 alone $\left(*, P<2 \times 10^{-5}\right)$. Q-VD blocks the Doc + ABT-737 increase in annexin + cells in

516 LNCaP and PC3. (C) Mitochondrial protein release assay and western blot showing increased

517 cytochrome c, Smac, AIF and decreased Bax in LNCaP cells treated with Doc + ABT-737

518 compared to Doc or ABT-737 alone, and control. In DU145 cells, cytochrome c, Smac, and AIF

519 mitochondrial release were similar in Doc + ABT-737 as in Doc alone. Cox IV protein is negative

520 indicating no mitochondrial contamination whereas actin is the positive control. +C for both

521 LNCaP and DU145 is lysate prepared from LNCaP cells using the standard method for total

522 proteins.

523 Figure 3 DU145 cells are resistant to ABT-737 because they are Bax null. (A) Trypan blue

524 exclusion assay showing that Doc + ABT-737 (DA) or 1198 + ABT-737 (98A) increases cell

525 death at $72 \mathrm{~h}$ in DU145/Bax compared to Doc (D) or 1198 (98) alone (*, $P<0.008$ ), whereas there

526 is no effect in DU145/EV (empty vector) control cells. Western blot analysis showing that DA or

527 98A increases cP in DU145/Bax cells compared to D or 98 alone, whereas there is no increase of

528 cP in DU/EV cells. Bax is expressed in DU145/Bax but not in DU145/EV cells. (B)

529 Annexin-FITC/PI flow cytometric analysis showing higher annexin+ and PI+ cells in DA treated 
DU145/Bax compared to DU145/EV cells (*, $\left.P<1 \times 10^{-6}\right)$. (C) Trypan blue exclusion assay

531 showing that DA or 98A does not significantly increase cell death in DU145/shMcl-1 and

532 DU145/shGFP control cells compared to D or 98 alone. Western blot analysis showing no

533 difference in the cP levels in DU145/shMcl-1 and DU145/shGFP control cells treated with D,

534 DA, 98, or 98A. Mcl-1 is expressed much higher in DU145/shGFP compared to DU145/shMcl-1

535 cells.

536 Figure 4 Bax suppression has a greater effect on ABT-737-mediated Doc/1198-induced

537 apoptotic cell death than Bak suppression in LNCaP cells. (A) Trypan blue exclusion assay

538 showing significantly less cell death in LNCaP/shBax and PC3/shBax cells treated with DA or

539 98A compared to shGFP (G) control cells $(*, P<0.02)$. Western blot analysis showing less cP and

540 Bax in LNCaP/shBax and PC3/shBax cells treated with DA or 98A compared to control cells. (B)

541 Trypan blue exclusion assay showing less cell death in PC3/shBak $\left({ }^{*}, P<6 \times 10^{-4}\right)$ but not in

542 LNCaP/shBak cells treated with DA or 98A compared to control cells. Western blot analysis

543 showing less cP in PC3/shBak cells treated with D or $98+$ A but little difference in LNCaP/shBak

544 cells compared to control cells. Bak is lower in LNCaP/shBak and PC3/shBak cells compared to

545 control cells.

546 Figure 5 Doc counteracts the ABT-737-mediated increase in Mcl-1 protein. Western blot

547 showing that treatment of LNCaP and PC3 cells with $1 \mu \mathrm{M}$ ABT-737 (A) increases Mcl-1 but

548 treatment with 1 nM Doc (D) decreases Mcl-1. Combination of Doc + ABT-737 (DA) decreases

549 Mcl-1. In LNCaP, there is less Bcl-2 (D, 24 h) and Bak (DA, 48 h) but few differences in Bcl-xL,

550 Bax, Bid, and Noxa. In PC-3, there are few differences Bcl-2, Bcl-xL, Bax, Bak, Bid, and Noxa.

551 Figure 6 Inhibition of cyclinB1/Cdk1-mediated phosphorylation of Bcl-2/Bcl-xL blocks

552 ABT-737 enhancement of Doc induced apoptosis in PC3 cells. (A) Trypan blue exclusion

553 assay showing that $5 \mu \mathrm{M}$ purvalanol A (P) lowers DA cell death in PC3 cells $\left(*, P<9 \times 10^{-8}\right)$. 
554 Western blot analysis showing that P blocks the DA increase in cl-PARP, P-Bcl-2 and P-Bcl-xL,

555 whereas there is no change in the total levels of Bcl-2 and Bcl-xL; P treatment increases Mcl-1 in

556 DA treated cells. Vertical line in cl-PARP indicates sample from same blot not in sequence. (B)

557 Trypan blue exclusion assay showing less cell death in DA treated PC3/shCyclin B1-2 and -3

558 cells compared to PC3/shGFP control cells $\left(*, P<4 \times 10^{-5}\right)$. Western blot analysis showing less

559 cyclin B1, cP, P-Bcl-2, P-Bcl-xL, and slightly greater Mcl-1 in PC3/shCyclin B1-2 and -3 cells

560 treated with DA compared to PC3/shGFP control cells.

561 Figure 7 ABT-737 enhancement of Doc-mediated apoptosis is more dependent on the ability

562 of cyclin B1/Cdk1 to decrease Mcl-1 than to phosphorylate Bcl-2/Bcl-xL. Trypan blue

563 exclusion assay showing greater cell death in DA treated (48 h) PC3/shCyclin B1/shMcl-1

564 (B1-2/M3, B1-3/M3) cells compared to control PC3/shCyclin B1/shGFP (B1-2/G, B1-3/G) and

565 PC3/shGFP (G) cells (*, $P<0.002)$. Western blot analysis showing increased cl-PARP and

566 decreased Mcl-1 in PC3/shCyclin B1/shMcl-1 compared control shGFP cells after DA treatment

567 (24 h). There is less cyclin B1, P-Bcl-1, and P-Bcl-xL in PC3/shCyclin B1/shGFP or shMcl-1

568 compared to PC3/shGFP cells, whereas there are no changes in total Bcl-1 or Bcl-xL.

569 Figure 8 Schematic of how ABT-737 can sensitize Bax+ CRPC cells to Doc. Treatment of

570 CRPC cells such as PC3 with Doc deregulates cyclin B1/Cdk1 activity and increases

571 phosphorylation of Bcl-2/Bcl-xL and degradation of Mcl-1. However, the high levels of

572 Bcl-2/Bcl-xL/Mcl-1 in CRPC cells presents a block to apoptosis. Addition of ABT-737 disrupts

573 the anti-apoptotic activity of Bcl-2/Bcl-xL and more effectively allows Doc treatment to bypass

574 the block and increase apoptosis. Cyclin B1/Cdk1 hyperactivity caused by Doc treatment also

575 lowers Mcl-1, an ABT-737 resistance factor, to further increase apoptosis. 


\section{Figure 1}

"Bcl-2 family protein levels and sensitivity to ABT-737 in PCa cells"

"(A) Western blot analysis showing that the levels of anti-apoptotic Bcl-2 and Bcl-xL proteins are higher in DU145 (D) and PC3 (P) CRPC cells compared toandrogen-dependent LNCaP (L) cells, whereas anti-apoptotic Mcl-1 is highest in DU145. The levels of pro-apoptotic Bax and Bak are higher in LNCaP compared to DU145 (Bax null) and PC3. After detection, Coomassie blue stain of total protein transferred to the membrane is the loading control. (B) Cell viabilityassay showing that LNCaP and PC3 are similarly sensitive to various concentrations of ABT-737 (1-5 m M; three days), whereas DU145 is more resistant."

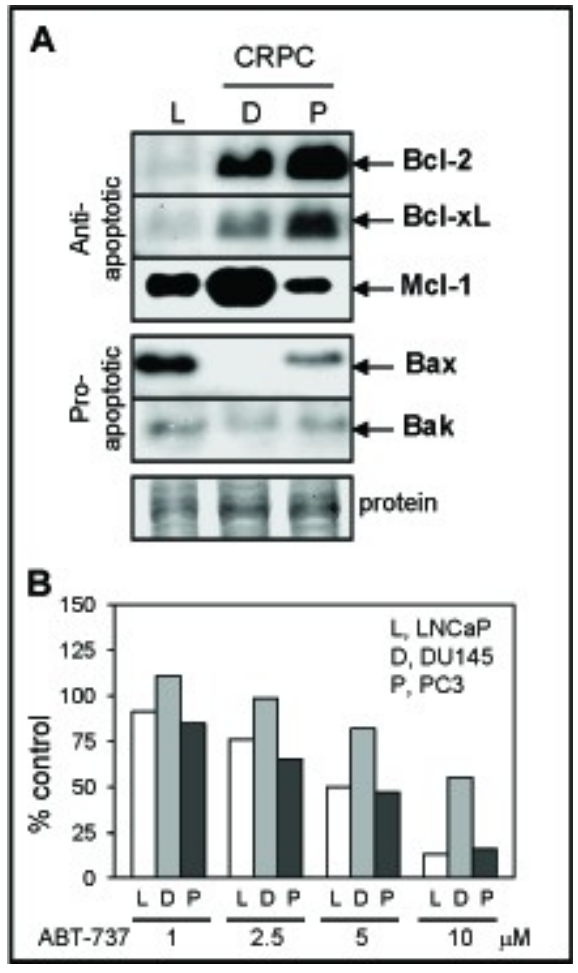




\section{Figure 2}

ABT-737 enhances Doc-mediated apoptotic cell death in LNCaP and PC3 but not in DU145 PCa cells

(A) Trypan blue exclusion assay showing that the combination of $1 \mathrm{nM}$ Doc $+1 \mathrm{uM} \mathrm{ABT-737}$

increases total cell death in LNCaP and PC3 but not in DU145 compared to Doc or ABT-737 alone (*, $\left.P<2 \times 10^{-4}\right)$. LNCaP were treated for $48 \mathrm{~h}$ and DU145 and PC3 for $72 \mathrm{~h}$. Pan-caspase inhibitor Q-VD (10 uM) blocks the Doc + ABT-737 increase in cell death. Western blot analysis showing that Doc + ABT-737 increases cleaved-PARP (cP) levels in LNCaP and PC3 but not in DU145 compared to Doc or ABT-737 alone. Q-VD blocks the Doc + ABT-737 increase in cP in all cells. (B) Flow cytometric analysis showing higher annexin-FITC stained LNCaP and PC3 but not DU145 cells treated with Doc + ABT-737 compared to Doc or ABT-737 alone $\left(*, P<2 \times 10^{-5}\right) \cdot$ Q-VD blocks the Doc + ABT-737 increase in annexin + cells in LNCaP and PC3. (C) Mitochondrial protein release assay and western blot showing increased cytochrome c, Smac, AIF and decreased Bax in LNCaP cells treated with Doc + ABT-737 compared to Doc or ABT-737 alone, and control. In DU145 cells, cytochrome c, Smac, and AIF mitochondrial release were similar in Doc + ABT-737 as in Doc alone. Cox IV protein is negative indicating no mitochondrial contamination whereas actin is the positive control. $+\mathrm{C}$ for both LNCaP and DU145 is lysate prepared from LNCaP cells using the standard method for total proteins. 


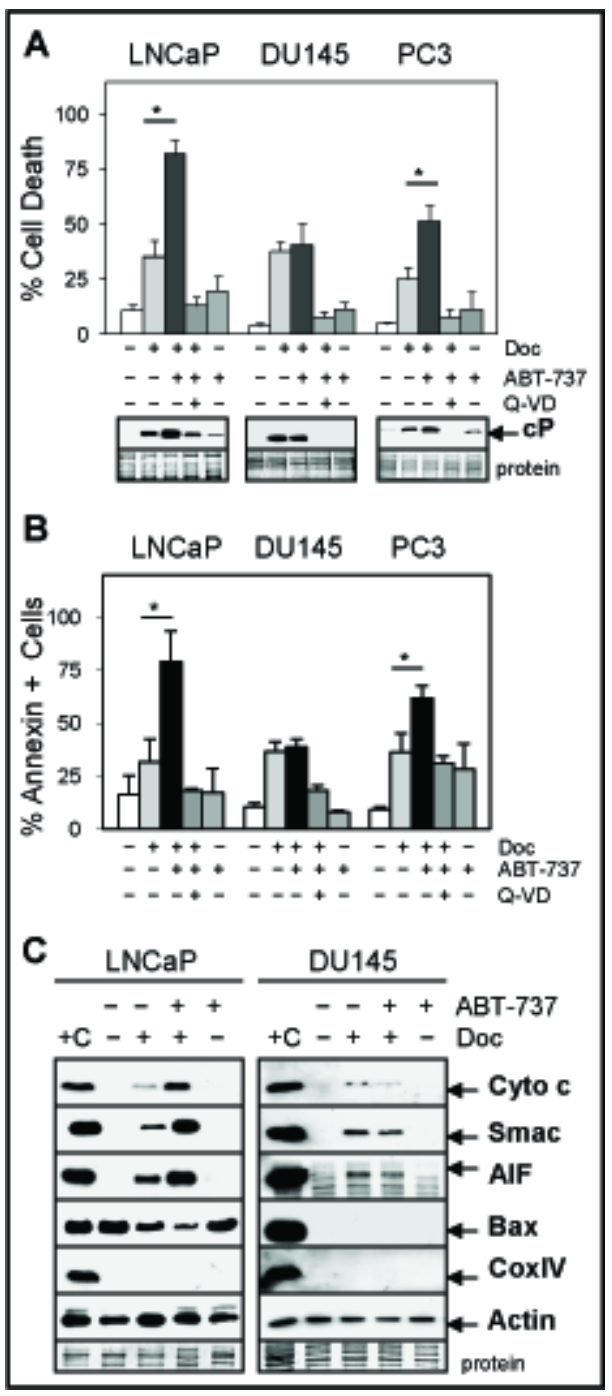




\section{Figure 3}

DU145 cells are resistant to ABT-737 because they are Bax null

(A) Trypan blue exclusion assay showing that Doc + ABT-737 (DA) or $1198+$ ABT-737 (98A) increases cell death at $72 \mathrm{~h}$ in DU145/Bax compared to Doc (D) or 1198 (98) alone (*, $P<0.008$ ), whereas there is no effect in DU145/EV (empty vector) control cells. Western blot analysis showing that DA or 98A increases cP in DU145/Bax cells compared to D or 98 alone, whereas there is no increase of cP in DU/EV cells. Bax is expressed in DU145/Bax but not in DU145/EV cells. (B) Annexin-FITC/PI flow cytometric analysis showing higher annexin+ and PI+ cells in DA treated DU145/Bax compared to DU145/EV cells $\left({ }^{*}, P<1 \times 10^{-6}\right)$. (C) Trypan blue exclusion assay showing that DA or 98A does not significantly increase cell death in DU145/shMcl-1 and DU145/shGFP control cells compared to D or 98 alone. Western blot analysis showing no difference in the cP levels in DU145/shMcl-1 and DU145/shGFP control cells treated with D, DA, 98, or 98A. Mcl-1 is expressed much higher in DU145/shGFP compared to DU145/shMcl-1 cells.






\section{Figure 4}

Bax suppression has a greater effect on ABT-737-mediated Doc/1198-induced apoptotic cell death than Bak suppression in LNCaP cells

(A) Trypan blue exclusion assay showing significantly less cell death in LNCaP/shBax and PC3/shBax cells treated with DA or 98A compared to shGFP (G) control cells (*, $P<0.02)$. Western blot analysis showing less $\mathrm{cP}$ and $\mathrm{Bax}$ in $\mathrm{LNCaP} / \mathrm{shBax}$ and $\mathrm{PC} / \mathrm{shBax}$ cells treated with DA or 98A compared to control cells. (B) Trypan blue exclusion assay showing less cell death in PC3/shBak (*, $\left.P<6 \times 10^{-4}\right)$ but not in LNCaP/shBak cells treated with DA or 98A compared to control cells. Western blot analysis showing less $\mathrm{cP}$ in $\mathrm{PC} / \mathrm{shBak}$ cells treated with $\mathrm{D}$ or $98+\mathrm{A}$ but little difference in LNCaP/shBak cells compared to control cells. Bak is lower in LNCaP/shBak and PC3/shBak cells compared to control cells.

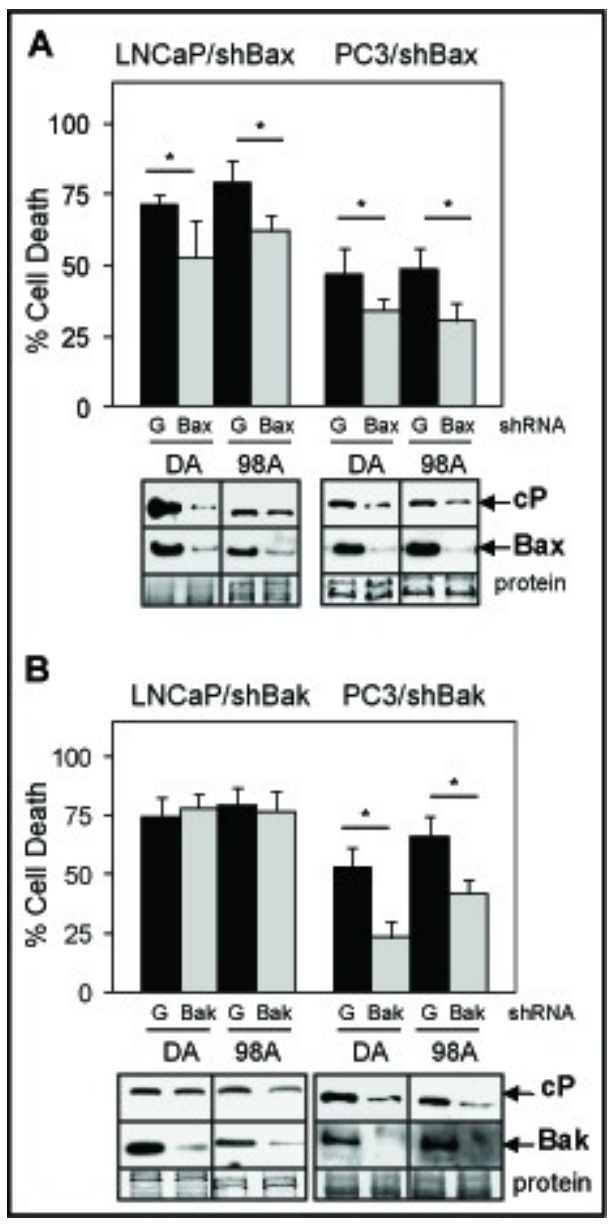




\section{Figure 5}

Doc counteracts the ABT-737-mediated increase in Mcl-1 protein

Western blot showing that treatment of LNCaP and PC3 cells with 1 uM ABT-737 (A) increases Mcl-1 but treatment with $1 \mathrm{nM}$ Doc (D) decreases Mcl-1. Combination of Doc + ABT-737 (DA) decreases Mcl-1. In LNCaP, there is less Bcl-2 (D, 24 h) and Bak (DA, 48 h) but few differences in Bcl-xL, Bax, Bid, and Noxa. In PC-3, there are few differences Bcl-2, Bcl-xL, Bax, Bak, Bid, and Noxa.

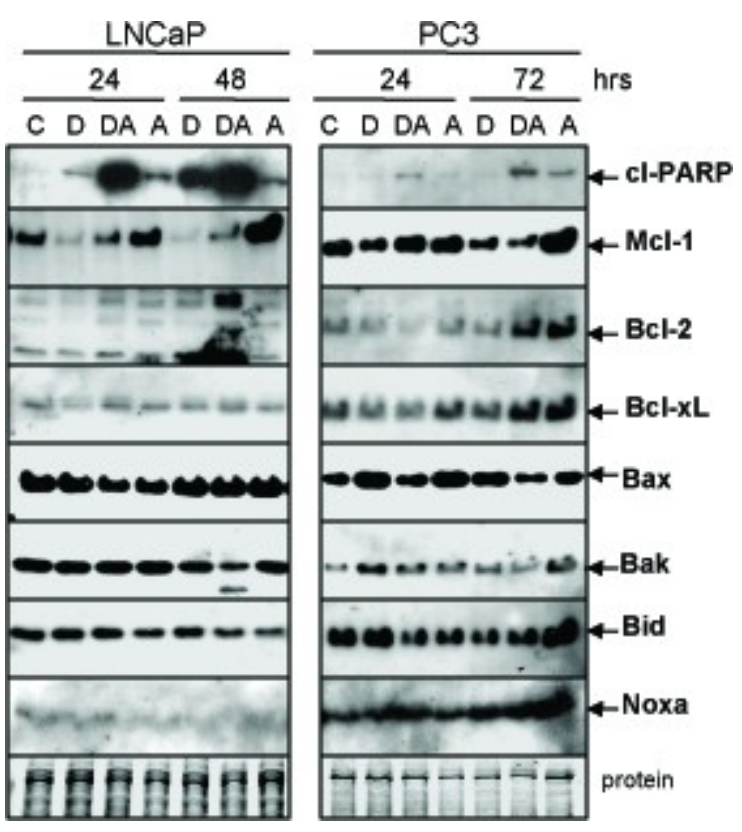




\section{Figure 6}

Inhibition of cyclinB1/Cdk1-mediated phosphorylation of Bcl-2/Bcl-xL blocks ABT-737 enhancement of Doc induced apoptosis in PC3 cells

(A) Trypan blue exclusion assay showing that $5 \mathrm{uM}$ purvalanol A (P) lowers DA cell death in PC3 cells $\left({ }^{*}, P<9 \times 10^{-8}\right)$. Western blot analysis showing that P blocks the DA increase in cl-PARP, P-Bcl-2 and $\mathrm{P}-\mathrm{Bcl}-\mathrm{xL}$, whereas there is no change in the total levels of $\mathrm{Bcl}-2$ and $\mathrm{Bcl}-\mathrm{xL} ; \mathrm{P}$ treatment increases Mcl-1 in DA treated cells. Vertical line in cl-PARP indicates sample from same blot not in sequence. (B) Trypan blue exclusion assay showing less cell death in DA treated PC3/shCyclin B1-2 and -3 cells compared to PC3/shGFP control cells $\left(*, P<4 \times 10^{-5}\right)$. Western blot analysis showing less cyclin B1, cP, P-Bcl-2, P-Bcl-xL, and slightly greater Mcl-1 in PC3/shCyclin B1-2 and -3 cells treated with DA compared to PC3/shGFP control cells.

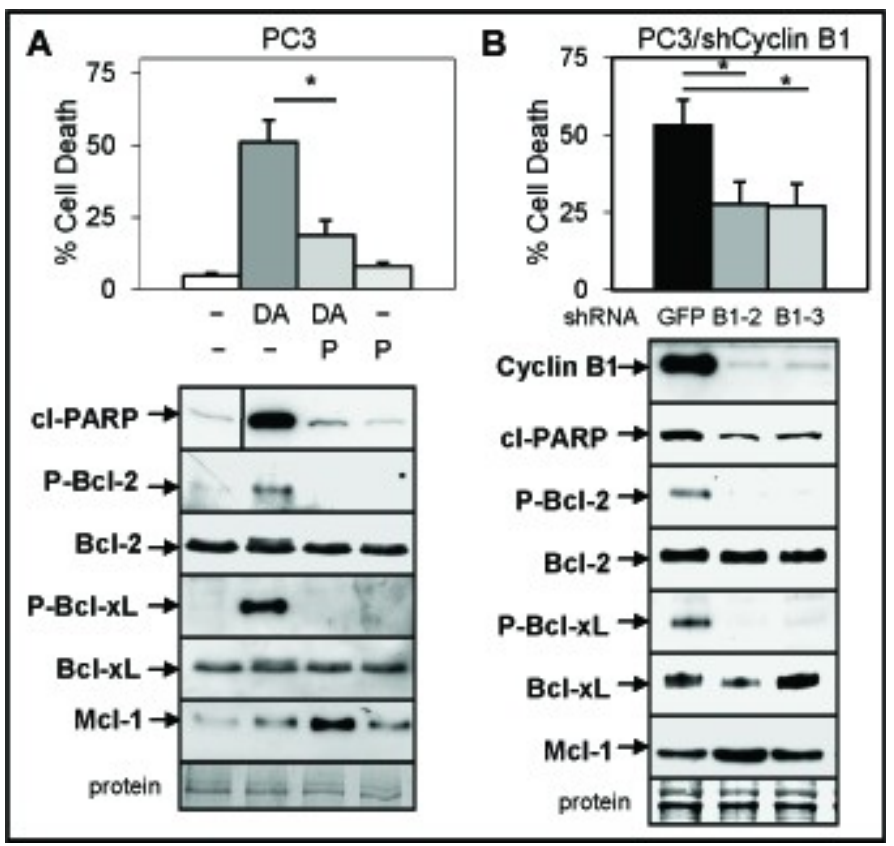




\section{Figure 7}

ABT-737 enhancement of Doc-mediated apoptosis is more dependent on the ability of cyclin B1/Cdk1 to decrease Mcl-1 than to phosphorylate Bcl-2/Bcl-xL

Trypan blue exclusion assay showing greater cell death in DA treated (48 h) PC3/shCyclin B1/shMcl-1 (B1-2/M3, B1-3/M3) cells compared to control PC3/shCyclin B1/shGFP (B1-2/G, B1-3/G) and PC3/shGFP (G) cells $(*, P<0.002)$. Western blot analysis showing increased cl-PARP and decreased Mcl-1 in PC3/shCyclin B1/shMcl-1 compared control shGFP cells after DA treatment (24 h). There is less cyclin B1, P-Bcl-1, and P-Bcl-xL in PC3/shCyclin B1/shGFP or shMcl-1 compared to PC3/shGFP cells, whereas there are no changes in total Bcl-1 or Bcl-xL.

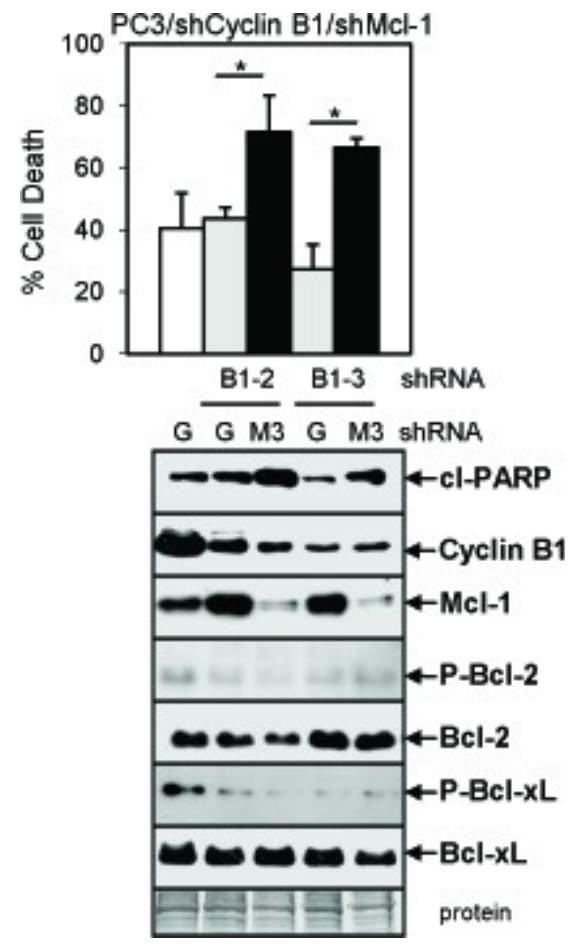




\section{Figure 8}

Schematic of how ABT-737 can sensitize Bax+ CRPC cells to Doc

Treatment of CRPC cells such as PC3 with Doc deregulates cyclin B1/Cdk1 activity and increases phosphorylation of Bcl-2/Bcl-xL and degradation of Mcl-1. However, the high levels of Bcl-2/Bcl-xL/Mcl-1 in CRPC cells presents a block to apoptosis. Addition of ABT-737 disrupts the anti-apoptotic activity of Bcl-2/Bcl-xL and more effectively allows Doc treatment to bypass the block and increase apoptosis. Cyclin B1/Cdk1 hyperactivity caused by Doc treatment also lowers Mcl-1, an ABT-737 resistance factor, to further increase apoptosis.

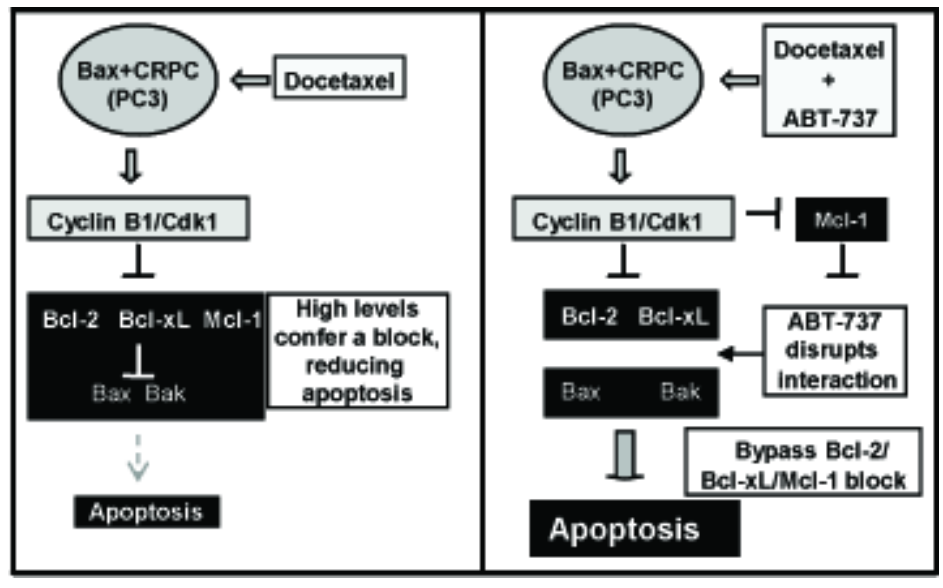

